\title{
Análisis del enfoque de derechos humanos y las políticas públicas en Colombia
}

\author{
Erika Hernández Valbuena ${ }^{1}$
}

\section{Resumen}

El resultado de los procesos políticos y sociales en el Estado colombiano ha permitido vincular y priorizar el enfoque de los derechos humanos en las políticas públicas, a través del desarrollo de mecanismos de participación ciudadana en los contextos de diseño e implementación de las mismas. En efecto, la adopción de políticas públicas se convierte en un instrumento adecuado para dar mayor concreción a los derechos, y por ende a la consolidación del Estado Social de Derecho. Es así como el enfoque de Derechos Humanos se convierte en una perspectiva de análisis para estructurar y diseñar políticas públicas acordes con las necesidades sociales reales, en función a la valoración del proceso de desarrollo humano dentro del proceso de concertación entre el Estado y la sociedad civil en Colombia.

$\mathrm{Al}$ respecto, y desde la concepción teórico-práctica, se realizará una descripción de los principios que desde la jurisprudencia rigen este enfoque. Además, se analizará su relación con las políticas públicas participativas y, finalmente, s e e xaminarán mecanismos a través de los cuales se logra su aplicabilidad en el contexto colombiano.

1 Candidata a Doctora en Derecho Internacional. Magister en Derechos Humanos y Derecho Internacional de los Conflictos Armados. Profesional en Relaciones Internacionales y Estudios Políticos. Profesora titular de la Facultad de Gobierno y Relaciones Internacionales de la Universidad Santo Tomás. Líder de Línea "Seguridad y Paz en escenarios transformados" de la Universidad Santo Tomás. 


\section{Introducción}

A partir del fin de la Guerra Fría y el auge de escenarios de violencia en contra de civiles, particularmente en el caso de la vulneración de no combatientes en la guerra de la ex Yugoslavia y el genocidio en Ruanda, académicos y políticos de diversas naciones iniciaron un profundo debate acerca de las medidas para garantizar la protección y vigencia de los Derechos Humanos (DDHH) en diferentes contextos del mundo. Esta pretensión, enfocada en la promoción y la defensa de los DDHH, expone una cierta conciencia universal acerca de la necesidad de garantizar un conjunto de derechos compatibles en todo el globo, los cuales son expresados en el Preámbulo a la Declaración Universal de Derechos Humanos, aprobada en 1948 por la entonces recién creada Organización de las Naciones Unidas (2008)

La libertad, la justicia y la paz en el mundo tienen por base el reconocimiento de la dignidad intrínseca y de los derechos iguales e inalienables de todos los miembros de la familia humana..., el desconocimiento y el menosprecio de los Derechos Humanos han originado actos de barbarie..., [es] esencial que los Derechos Humanos sean protegidos por un régimen de Derecho, a fin de que el hombre no se vea compelido al supremo recurso de la rebelión contra la tiranía y la opresión...

En este sentido es posible entender la pretensión en torno a la necesidad de encontrar medios prácticos para extender el respeto a este conjunto de normas y principios, procurando extender el referente de participación desde una perspectiva de inclusión de mecanismos que permitan encajar una perspectiva de DDHH en las políticas públicas de un Estado.

Con la inclusión de una perspectiva de DDHH en políticas públicas es posible promover el fortalecimiento de la capacidad de incidencia política de los sujetos de derecho, garantizando mecanismos que tiendan a incentivar el respeto y el reconocimiento de los DDHH.

En el caso colombiano, un eje de estudios de los temas de DDHH en las políticas públicas ha estado interesado en abordar la consolidación de la normatividad internacional en relación con la protección y promoción de los derechos en el país, a partir de lo cual se deduce la necesidad de ampliar el trabajo en su profundización y consolidación. (PNUD, 2012, p. 12). Sin embargo, han sido pocos los análisis acerca de los mecanismos que se pueden utilizar para promover los derechos humanos en las políticas públicas.

Con el ánimo de adentrarse en el estudio de dichos mecanismos, el documento se estructurará en el siguiente sentido: en primer lugar se realizará una breve reflexión acerca de los principios y estándares que ha delineado la jurisprudencia de la Corte 
Constitucional de Colombia para garantizar una perspectiva de DDHH en el desarrollo e implementación de políticas públicas, derivadas del reconocimiento de un abanico de derechos ideales de un sistema político democrático. En segunda instancia, se analizarán las disposiciones aceptadas en el ordenamiento jurídico colombiano que materializan la creación de mecanismos con una perspectiva de DDHH en políticas públicas, así como la materialización misma de dichos mecanismos en el ordenamiento jurídico. Finalmente, se abordarán algunos cuestionamientos acerca de una perspectiva de DDHH en políticas públicas a la luz de los planteamientos de los acuerdos de La Habana.

\section{Principios rectores de DDHH en la formulación de políticas públicas}

Un análisis sobre el rol de los DDHH en las políticas públicas de un Estado debe reconocer el fundamento que brinda un Estado Social de Derecho a los requisitos de participación incluyente, amplia, informada y eficaz en torno a las políticas públicas que impactan a los ciudadanos.

Esto se deriva del reconocimiento que se hace en la Constitución Política de 1991 del país como un Estado incluyente y participativo, lo que supone un importante avance si se piensa que en el anterior ordenamiento jurídico el epicentro de la participación no estaba establecido expresamente en la Carta Magna.

En la Constititución de 1991, el Estado se fija como un fin esencial el facilitar la participación de todos en las decisiones que los afectan y en la vida económica, política, administrativa y cultural de la Nación (Art. 2), para lo cual se deben reacomodar las estructuras políticas que sustentan la relación entre el ciudadano y la administración pública.

Este cambio ideológico en el reconocimiento de los sujetos de derecho está sustentando en la idea de que cualquier ciudadano tiene derecho a participar en la conformación, ejercicio y control del poder político (Art. 40), para lo cual se diseñan algunos mecanismos administrativos y judiciales tendientes a garantizar que la perspectiva de los múltiples sujetos que conforman la ciudadanía se aprecia en los actos que les afectan o incumben.

La pretensión de incluir una perspectiva participativa en la formulación e implementación de políticas públicas tiene como finalidad reducir el margen de conflictividad social derivado de usos, derechos o visiones distintas respecto al uso de los recursos o de la acción del Estado.

Según la FAO (2001), es previsible que las políticas impuestas sin participación local o con una inadecuada identificación y consulta de los actores, de la cual se 
derivan errores en la información existente o en la forma en cómo es compartida, se transforme progresivamente hacia escenarios en los cuales maduren conflictos latentes entre las partes. En este sentido, como ejercicio de superación de las limitaciones de las debilidades institucionales y con el fin de garantizar el control y evaluación de los proyectos, se requiere una estrategia para mejorar la comunicación y el intercambio de información entre los distintos grupos de interés.

Esta estrategia debe tener presente el principio de progresividad y no discriminación en el acceso pleno a derechos contenidos en tratados internacionales de derechos humanos ratificados por Colombia. Por este motivo, y con el fin de garantizar que las políticas públicas -en general- y los actos administrativos que afecten la vida de los ciudadanos en particular- tengan en cuenta las expectativas y los alcances sobre los mismos, la Corte Constitucional ha fijado algunos principios y parámetros que deben tener en cuenta las autoridades en torno a la participación ciudadana, así:

"El derecho a la participación se encuentra previsto en la Constitución para todos los colombianos, como una manifestación del principio democrático del Estado Social de Derecho. Asimismo, se deriva de disposiciones como el artículo $2^{\circ}$ de la Carta, conforme al cual, entre los fines esenciales del Estado, se encuentra el de facilitar la participación de todos en las decisiones que los afectan y en la vida económica, política, administrativa y cultural de la Nación, y el artículo 40 Superior, que consagra, para todo ciudadano, el derecho de participar en la conformación, ejercicio y control del poder político. Igualmente, el derecho a participar de las decisiones de la administración que les interesan a los ciudadanos, se encuentra reconocido en el ámbito internacional por varios instrumentos" (Corte Constitucional, 2012).

El primer criterio que ha fijado la Corte para la participación de la ciudadanía en programas, proyectos o políticas públicas que impliquen una afectación de sus derechos, y en particular de los derechos medioambientales, está asociado a la idea de que la participación debe ser previa a la realización del mismo. En este sentido, es llamativa la Sentencia T-348 del 2012, en la cual la Corte manifiesta que:

... De la misma forma, como parte de las decisiones que toma la administración y que afectan las tradiciones y la vida diaria de las poblaciones, el derecho al debido proceso administrativo y el derecho a la participación, obligan a concertar con la comunidad las medidas previas, interinas y posteriores que se adoptarán en el desarrollo de la ejecución del proyecto, encaminadas a proteger sus derechos fundamentales (Corte Constitucional, 2012). 
En esta providencia, la Corte manifiesta que la participación previa supone un reconocimiento importante de la opinión de la ciudadanía, toda vez que se deben contemplar los valores, los intereses y las expectativas de los habitantes de un territorio en relación con el mismo, o dicho de otro modo, no se pueden abandonar los verdaderos espacios de concertación teniendo en cuenta los intereses de la comunidad afectada y no solo los del proyecto a realizar.

Sin embargo, el derecho a la participación debe tener como característica en particular, asociada a la mayor cantidad de conocimiento real de los temas pertinentes, o dicho en palabras de la Corte, la información oficial debe ser completa, consistente, coherente, verificable, comparable, contextualizada, diáfana y siempre oportuna (Corte Constitucional, Sentencia C-891, 2002).

Según la sentencia anteriormente mencionada, en procura de materialización el derecho a la participación, y en particular en aquellos casos en los que las decisiones afectan o puedan llegar a afectar los intereses y derechos de los ciudadanos, le corresponde a las entidades estatales suministrarle a las personas oportunamente toda la información que no goce de reserva constitucional o legal, con las características anteriormente mencionadas.

Según lo planteado por la Corte, el derecho a la información, cuando es efectivo y eficientemente garantizado, se convierte en un instrumento de reflexión y acción (individual y colectiva), en el entendido de que las autoridades estatales, a más de esa información, deben asumir la promoción, creación y fomento de las condiciones idóneas para la discusión pública a través del fortalecimiento del debate democrático, fundamento principal de una democracia deliberativa. En este sentido, recuerda la Corte, la participación ciudadana en esos ámbitos de discusión constructiva supone el recíproco respeto de los criterios expuestos por los interlocutores y la apertura de oportunidades para todos los ciudadanos, en relación con la defensa de sus derechos (Corte Constitucional, Sentencia C-891, 2002).

En ese orden de ideas, es menester, previo a realizar cualquier análisis de los mecanismos que permiten la participación en la formación y seguimiento de políticas públicas con un enfoque de $\mathrm{DDHH}$, resaltar que desde la jurisprudencia de la Corte Constitucional, que es la entidad autorizada para definir e interpretar los alcances de la Carta Política, existe un importante cambio ideológico y dogmático que determinó una tendencia aperturista de la participación política, con la Constitución Política de 1991, mediante la cual se establecen mecanismos especiales a la ciudadanía, lo que representó una reivindicación en sus derechos fundamentales como integrantes tanto en lo individual como en lo colectivo de un Estado Social y Democrático de Derecho.

El Estado colombiano se funda, según el preámbulo y el Artículo primero de la Constitución de 1991, en el reconocimiento de la pluralidad, la participación, la igualdad y la libertad de las personas, configurando a Colombia como un Estado 
Social y Democrático de Derecho, diferenciándose sustancialmente de lo que establecía la Constitución de 1886. Así, la república se estructuró a partir de la idea de un Estado participativo, razón por la cual propende por la protección de los derechos fundamentales de los ciudadanos.

\section{Normas vinculantes en el ordenamiento jurídico colombiano}

Tal como lo reconoce Sañudo (2014), es importante conceptualizar ampliamente el derecho específico sobre el cual se está haciendo énfasis con el fin de verificar la existencia de instrumentos vinculantes y no vinculantes que impactan en la formación del mismo, así como el diseño y despliegue de otros mecanismos que pueden incentivar su respeto y ejercicio en las prácticas cotidianas de la ciudadanía. Para tal fin es importante garantizar mecanismos de protección y de mecanismos de incidencia política en DDHH.

Por otra parte, Sañudo (2014) señala tres elementos básicos para la posibilidad de incidencia de perspectivas de derechos humanos en políticas públicas. La primera está relacionada con la existencia de una institucionalidad adecuada para la protección y el respeto de los DDHH. La segunda está estrechamente vinculada a las garantías del derecho a la participación ciudadana. Finalmente se requiere de una ciudadanía activa y participativa que pueda hacer uso de dichas garantías.

Una primera aproximación al reconocimiento de la institucionalidad adecuada para la protección y el respeto de los DDHH parte de reconocer las obligaciones para el Estado y dentro de las cuales suscitan especial mención como antecedente y justificación normativa al establecimiento de una perspectiva de derechos humanos en el desarrollo e implementación de una política pública, bajo los principios y lineamientos que ha identificado la Corte Constitucional a través de la jurisprudencia que ha definido para ello. Por otra parte, es menester recordar que el Estado colombiano se obliga ante el sistema internacional, al ratificar algunos instrumentos de derechos humanos, los cuales ingresan al ordenamiento con fuerza vinculante a través de su ingreso al Bloque de Constitucionalidad: 
Tabla 1. Instrumentos vinculantes y no vinculantes aplicados en Colombia

\begin{tabular}{|c|c|c|}
\hline Instrumento vinculante & Norma colombiana & Instrumento no vinculante \\
\hline $\begin{array}{l}\text { 1. Pacto internacional de derechos } \\
\text { 2. Panómicos, sociales y culturales. } \\
\text { Piviles y Políticos. } \\
\text { 3. Convención Internacional sobre la } \\
\text { Eliminación de todas las Formas de } \\
\text { Discriminación Racial. } \\
\text { 4. Convención sobre el Estatuto de los } \\
\text { Refugiados. } \\
\text { 5. Convención sobre la Eliminación de } \\
\text { todas las Formas de Discriminación } \\
\text { contra la mujer. } \\
\text { 6. Convención sobre los Derechos de } \\
\text { los Niños. } \\
\text { 7. Convención contra la Tortura } \\
\text { y otros Tratos o Penas Crueles, } \\
\text { Inhumanas o Degradantes. } \\
\text { 8. Convención Internacional sobre } \\
\text { la Protección de los Derechos de } \\
\text { todos los Trabajadores Migratorios } \\
\text { y de sus Familias. } \\
\text { 9. Convención de los Derechos de las } \\
\text { Personas con Discapacidad. } \\
\text { 10. Convención Internacional para la } \\
\text { protección de todas las Personas } \\
\text { contra las Desapariciones Forzadas. }\end{array}$ & $\begin{array}{ll}\text { 1. } & \text { Ley } 74 \text { de } 1968 . \\
\text { 2. } & \text { Ley } 74 \text { de } 1968 . \\
\text { 3. } & \text { Ley } 22 \text { de } 1981 . \\
4 . & \text { Ley } 31 \text { de } 1961 . \\
\text { 5. } & \text { Ley } 51 \text { de } 1981 . \\
\text { 6. } & \text { Ley } 12 \text { de } 1991 . \\
\text { 7. } & \text { Ley } 70 \text { de } 1986 . \\
\text { 8. } & \text { Ley } 146 \text { de } 1994 . \\
\text { 9. } & \text { Ley } 1346 \text { de } 2009 . \\
\text { 10. } & \text { Ley } 1418 \text { de } 2010 .\end{array}$ & $\begin{array}{l}\text { 1. } \begin{array}{l}\text { Observaciones genera- } \\
\text { les de los comités crea- } \\
\text { dos para la supervisión } \\
\text { de los pactos. }\end{array} \\
\text { 2. } \begin{array}{l}\text { Resoluciones del } \\
\text { Consejo de Seguridad } \\
\text { de la ONU. }\end{array} \\
\text { 3. } \begin{array}{l}\text { Informes de relatores } \\
\text { especiales de derechos }\end{array} \\
\text { humanos. } \\
\text { 4. } \begin{array}{l}\text { Documentos de trabajo } \\
\text { de organismos de la }\end{array} \\
\text { ONU. } \\
\text { 5. } \begin{array}{l}\text { Declaraciones de princi- } \\
\text { pios básicos. }\end{array} \\
\text { 6. Relatorías por } \\
\text { temáticas. } \\
\text { Visitas in loco } \\
\text { (Fact-Fini). }\end{array}$ \\
\hline
\end{tabular}

Fuente: Sañudo, M. y Sánchez, R. (2014), Enfoque Basado en Derechos humanos. Guía para su uso en incidencia política y políticas públicas: Bogotá (Colombia), Editorial Pontificia Universidad Javeriana.

Así mismo, el Estado ha ratificado algunos instrumentos de carácter regional vinculantes y otros no vinculantes, desde los cuales se puedan crear condiciones óptimas a partir de las cuales garantizar un ejercicio efectivo del derecho: 
Tabla 2. Instrumentos vinculantes y no vinculantes regionales aplicados en Colombia

\begin{tabular}{|c|c|c|}
\hline Instrumento vinculante & Norma colombiana & Instrumento no vinculante \\
\hline $\begin{array}{l}\text { 1. Convención Americana de } \\
\text { 2. Perechos Humanos. } \\
\text { 3. Protocolo de San Salvador. } \\
\text { Convención Interamericana para } \\
\text { Prevenir y Sancionar la Tortura. } \\
\text { Protocolo de la Convención ame- } \\
\text { ricana sobre Derechos Humanos } \\
\text { Relativos a la Pena de Muerte. } \\
\text { 5. Convención Interamericana para } \\
\text { Prevenir, Sancionar y Erradicar la } \\
\text { Violencia contra la Mujer. } \\
\text { 6. Convención Interamericana } \\
\text { para la Eliminación de Todas las } \\
\text { Formas de Discriminación contra } \\
\text { las Personas con Discapacidad. }\end{array}$ & $\begin{array}{ll}\text { 1. } & \text { Ley } 16 \text { de } 1972 . \\
2 . & \text { Ley } 319 \text { de } 1996 . \\
\text { 3. } & \text { Ley } 409 \text { de } 1997 . \\
4 . & \text { Ley } 1410 \text { de } 2010 . \\
5 . & \text { Ley } 1258 \text { de } 2007 . \\
6 . & \text { Ley } 762 \text { de } 2002 .\end{array}$ & $\begin{array}{l}\text { 1. } \begin{array}{l}\text { Declaración Americana } \\
\text { de Derechos y Deberes } \\
\text { del Hombre. }\end{array} \\
\text { 2. Proyecto de Declaración } \\
\text { Americana sobre los } \\
\text { Derechos de los Pueblos } \\
\text { Indígenas. } \\
\text { 3. Declaración sobre la } \\
\text { Libertad de Expresión. } \\
\text { 4. Carta Democrática } \\
\text { Americana. }\end{array}$ \\
\hline
\end{tabular}

Fuente: Sañudo, M.y Sánchez, R. (2014), Enfoque Basado en Derechos humanos. Guía para su uso en incidencia política y políticas públicas: Bogotá (Colombia), Editorial Pontificia Universidad Javeriana.

A partir del reconocimiento de este marco normativo, es preciso mencionar que la inclusión de una perspectiva de DDHH en las políticas públicas se debe sustentar en el reconocimiento de la diversidad étnica, política, social y cultural del país, pues debe entenderse dentro del marco del derecho fundamental a la igualdad en sentido material; es decir, concebir, según lo planteado por la Corte Constitucional en sentencia C-359 de 2013, debe entenderse "al Estado Social de Derecho como el ente que debe corregir desigualdades existentes entre iguales mediante la promoción de la inclusión y la participación, garantizando a aquellos grupos en situación de segregación, el efectivo goce de sus derechos fundamentales, entre los que se encuentra el de la diversidad étnica y cultural, el derecho al territorio, el derecho a la autonomía y a la consulta previa".

Un ejemplo llamativo de los mecanismos diseñados para la participación en políticas públicas está relacionado con los preceptos derivados del Artículo 79 de la Constitución Política de 1991, el cual consagra que: “Todas las personas tienen derecho a gozar de un ambiente sano. La ley garantizará la participación de la comunidad en las decisiones que puedan afectarlo. Es deber del Estado proteger la diversidad e integridad del ambiente, conservar las áreas de especial importancia ecológica y fomentar la educación para el logro de estos fines".

A propósito del mismo, la Corte Constitucional, en su Sentencia T-297/2014, declaró que las políticas públicas que impacten el medioambiente deben incorporar 
mecanismos que garanticen esquemas de justicia participativa en los siguientes términos:

...Un reclamo de participación significativa de los ciudadanos, en particular de quienes resultarán efectiva o potencialmente afectados por la ejecución de determinada actividad. Esta dimensión comporta la apertura de espacios en donde los afectados puedan participar en la toma de decisiones relativas a la realización del proyecto, la evaluación de sus impactos, permitiendo que al lado del conocimiento técnico experto que suele ser el único tenido en cuenta para orientar la toma de decisiones en materia ambiental, también haya un espacio significativo para el conocimiento local, que se expresa en la evaluación nativa de los impactos y en la definición de las medidas de prevención, mitigación y compensación correspondientes (Corte Constitucional, Sentencia T-297, 2014).

Los mecanismos administrativos de participación e inclusión de una perspectiva de DDHH en políticas públicas en Colombia deben converger ante una multiplicidad de problemáticas y alternativas de solución, en un marco de actores heterogéneos con intereses, visiones y expectativas, muchas veces contradictorias. Sin embargo, siempre deben tener en cuenta que "un enfoque basado en los derechos humanos identifica a los ciudadanos y ciudadanas como titulares de éstos, el contenido de los derechos, y los correspondientes titulares de deberes y las obligaciones (Estado), procurando fortalecer las capacidades de los primeros para demandar su vigencia y de los segundos, para realizarlos o crear condiciones para su vigencia” (DHES, 2014, p. 55).

En este sentido, es preciso delinear algunos mecanismos administrativos a través de los cuales es posible hacer efectivos los derechos a la participación previa, informada, representativa, eficaz y respetuosa de una visión dialógica de las relaciones entre el ciudadano y la administración pública, a partir de los cuales se pueda incluir una perspectiva de DDHH en el diseño, la implementación y la evaluación de las políticas públicas. 
Tabla 3. Mecanismos Administrativos de participación e inclusión de una perspectiva de DDHH en políticas públicas

\begin{tabular}{|ll|}
\hline 1. & Consulta popular. \\
2. & Cabildo abierto. \\
3. & Audiencias públicas. \\
4. & Intervención de terceros. \\
5. & Consulta previa. \\
\hline
\end{tabular}

Fuente: elaboración propia.

\section{Consulta popular}

La consulta popular es un mecanismo de participación democrática consagrado por la Constitución Política de 1991, tendiente a garantizar un amplio margen de participación ciudadana en la conformación de políticas, programas y proyectos que impacten la vida social. Esto implica que los planes de desarrollo deben incluir medidas específicas orientadas a promover la participación de todas las personas en las decisiones que los afectan y el apoyo a las diferentes formas de organización de la sociedad.

Esta decisión está contemplada en el Artículo 33 de la Ley 136/94, en donde se establece que:

...Cuando el desarrollo de proyectos de naturaleza turística, minera o de otro tipo, amenace con crear un cambio significativo en el uso del suelo, que dé lugar a una transformación en las actividades tradicionales de un municipio, se deberá realizar una consulta popular de conformidad con la Ley. La responsabilidad de estas consultas estará a cargo del respectivo municipio.

La consulta puede ser de carácter municipal, departamental o nacional. En el caso de una consulta de carácter nacional, el Presidente de la república, con el previo aval del Congreso y respaldado por las firmas de todos los ministros, es el encargado de consultar al pueblo cuando crea que una decisión próxima a ser tomada es de trascendencia nacional; es decir, que afecta a todo el territorio del Estado. Así mismo, la consulta popular podrá ser de iniciativa ciudadana cuando se registre ante la registraduría nacional y se cuente con el apoyo de un número de ciudadanos igual o superior al $5 \%$ del censo electoral en la fecha respectiva.

Por otra parte, en el caso de las consultas populares a nivel distrital, departamental, municipal o local, la decisión de convocarlas no es tomada por el Presidente sino por los 
gobernadores y alcaldes, según sea el caso, para lo cual no se debe acudir al Congreso para que éste la respalde sino que los gobernadores o alcaldes deben cumplir ciertos requisitos que están claramente definidos en el estatuto general de la organización territorial. Así mismo, en el Artículo 9 de la Ley 1757 de 2015 se abre la posibilidad para una consulta popular de origen ciudadano en las entidades territoriales, la cual requiere del apoyo de un número no menor del $10 \%$ de ciudadanos que hagan parte del respectivo censo electoral.

Un asunto llamativo en este aspecto es la obligatoriedad en la decisión tomada. así pues, las entidades a las cuales les corresponda ejecutar lo que en la consulta se haya decidido tienen tres meses para hacerlo, reafirmando la inclusión de una perspectiva participativa y de igualdad de derechos entre los sujetos que sustentan el poder político.

\section{Cabildo abierto}

El cabildo abierto es un mecanismo administrativo de participación política que puede promover una perspectiva de participación e inclusión en la formulación de políticas públicas del orden local. Según el Artículo 9 de la Ley 134 de 2011, el cabildo abierto "es la reunión pública de los concejos distritales, municipales o de las juntas administradoras locales, en la cual los habitantes pueden participar directamente con el fin de discutir asuntos de interés para la comunidad".

Según la misma Ley 134, el cabildo abierto debe ser solicitado ante la secretaría de la respectiva corporación la solicitud razonada para que sea discutido un asunto en cabildo abierto, con no menos de 15 días de anticipación a la fecha de iniciación del período de sesiones, por un número no inferior al $5 \times 1.000$ del censo electoral del municipio, distrito, localidad, comuna o corregimiento.

El Artículo 83 es claro respecto al hecho de que puede ser materia de cabildo abierto cualquier asunto de interés para la comunidad, razón por la cual pueden asistir todas las personas que tengan interés en el asunto, lo cual abre la posibilidad de un amplio marco de participación para que la ciudadanía apoye la construcción de condiciones óptimas para hacer un ejercicio efectivo del derecho o, siquiera, el despliegue de estrategias necesarias para cumplir con las obligaciones institucionales.

Este mecanismo supone espacios de rendición de cuentas, a través de la posibilidad de citar a funcionarios municipales o distritales, con cinco (5) días de anticipación, para que concurran al cabildo y para que respondan, oralmente o por escrito, sobre hechos relacionados con el tema del cabildo. 
Este mecanismo permite garantizar espacios de pluralidad, así como la participación, la igualdad y la libertad de las personas, reafirmando los postulados constitucionales contenidos en la carta política de 1991.

\section{Audiencias públicas}

Las audiencias públicas son mecanismos de participación ciudadana que pueden ser solicitados tanto por las entidades públicas como por los ciudadanos interesados en el desarrollo de algún tema que les afecte. En primer lugar, las entidades las pueden convocar para tratar aspectos relacionados con la formulación, ejecución o evaluación de políticas y programas a su cargo, según lo plantea el Artículo 33 de la Ley 489/1998.

Esto conlleva el reconocimiento de los derechos e intereses colectivos e individuales que pueden verse afectados en el marco de la realización de políticas públicas. En este sentido, manifiesta el desarrollo de una institucionalidad para la protección y el respeto de las posibilidades de participación. Además, constituye en sí misma una garantía del derecho a la participación ciudadana, quedando sujeta a una ciudadanía activa y participativa que pueda hacer uso de dichas garantías.

Respecto a esta misma, es claro que las comunidades y organizaciones las pueden solicitar, sin que las decisiones allí adoptadas sean vinculantes, aunque sí ampliamente explicativas de las decisiones tomadas.

Por otra parte, el Código de Procedimiento Administrativo y de lo Contencioso Administrativo (Ley 1437 de 2011) establece, en su Artículo 35, que dentro de procedimientos administrativos las autoridades podrán decretar audiencias para promover la participación ciudadana. Taxativamente, el artículo resalta: "Las autoridades podrán decretar la práctica de audiencias en el curso de las actuaciones con el objeto de promover la participación ciudadana, asegurar el derecho de contradicción, o contribuir a la pronta adopción de decisiones. De toda audiencia se dejará constancia de lo acontecido en ella".

Las audiencias mencionadas pueden ser solicitadas, razón por la cual pueden eventualmente ser de carácter facultativo.

En algunas temáticas específicas, particularmente en temas ambientales, las audiencias públicas tienen connotaciones específicas relacionadas con la posibilidad de dar a conocer los impactos del proyecto y las medidas de manejo propuestas y recibir opiniones, información, documentos y cualquier tipo de elementos que permitan una relación más participativa de la ciudadanía. 
Según el Artículo 72 de la Ley 99 de 1993, las audiencias de carácter ambientalpública que se celebrarán ante la autoridad competente para el otorgamiento del permiso o la licencia ambiental respectiva, pueden ser solicitadas por el Procurador General de la Nación o el Delegado para Asuntos Ambientales, el Defensor del Pueblo, el Ministro del Medio Ambiente, las demás autoridades ambientales, los gobernadores, los alcaldes o por lo menos cien (100) personas o tres (3) entidades sin ánimo de lucro, cuando se desarrolle o pretenda desarrollarse una obra o actividad que pueda causar impacto al medioambiente o a los recursos naturales renovables, y para la cual se exija permiso o licencia ambiental conforme a la Ley o a los reglamentos.

En este caso es llamativo el mecanismo de participación en el otorgamiento de la licencia ambiental si se reconoce que debe ser desarrollado con anticipación al acto que le ponga término a la actuación administrativa, bien sea para la expedición, la modificación o la cancelación de un permiso o licencia ambiental. Una vez que se realiza el procedimiento, el acto administrativo que otorga, niega o modifica la licencia debe tener en cuenta lo que pase en la audiencia.

Según se deduce de lo planteado por el Artículo 72 de la mencionada norma, la audiencia pública deberá ser convocada por la autoridad administrativa ante la cual se solicita, mediante edicto, con una anticipación de por lo menos 30 días a la toma de la decisión a debatir. El edicto comunicará la fecha, el lugar y la hora de celebración y el objeto de la audiencia. Por otra parte, y en tanto mecanismo de rendición de cuentas y de transparencia institucional, la audiencia deberá ser presidida por el jefe de la entidad competente o su delegado. El edicto permanecerá fijado en secretaría por 10 días, dentro de los cuales deberá ser publicado en un diario de circulación nacional y en el boletín de la respectiva entidad.

\section{Intervención de terceros}

Este mecanismo administrativo, desarrollado por el Artículo 38 del Código de Procedimiento Administrativo y de lo Contencioso Administrativo (Ley 1437 de 2011), contempla la posibilidad de que en procesos administrativos los terceros pueden intervenir cuando resulte afectado: (1) con la actuación administrativa adelantada en interés particular, o (2) cuando la decisión que sobre ella recaiga pueda ocasionarles perjuicios.

Detrás de este mecanismo se encuentra la posibilidad de que los ciudadanos afectados por una acción administrativa accedan al derecho al libre e igualitario acceso a las autoridades administrativas, a obtener decisiones motivadas, al debido proceso y a impugnar las decisiones ante autoridades de jerarquía superior, entre otras. 
En este caso en particular, el ciudadano debe enviar una petición de inclusión como tercero afectado y las pruebas que sustentan su solicitud. Al respecto de dicha solicitud, la autoridad que la tramita resolverá si acepta o no, aunque se establece que contra dicha decisión no procede recurso alguno.

En lo atinente a la decisión, la norma precisa que esta deberá ser motivada y se producirá una vez se hayan oído las opiniones de todos los interesados, con fundamento en las pruebas e informes disponibles y en la cual se resolverán las peticiones oportunamente planteadas por el peticionario o los terceros reconocidos. Así mismo, se consagra que cuando se trate de decisiones discrecionales, deben ser adecuadas a la norma que la autoriza y proporcionales a los hechos que le sirven de causa (artículos 42 y 43 ).

Por otra parte, esta figura puede ser usada para participar activamente en campos específicos, particularmente el ambiental. Así se contempla en el Artículo 69 de la Ley 99 de 1993, en donde se advierte que en procesos de licenciamiento ambiental cualquier persona (natural o jurídica) puede intervenir como tercero sin tener que demostrar interés jurídico alguno.

\section{Consulta previa}

En tanto procedimiento administrativo con enfoque diferencial, la consulta previa se ha convertido en el instrumento de las comunidades étnicas (indígenas, negras, palenqueras, raizales y ROM) más importante del país. Este derecho está consagrado, constitucionalmente, a través de la aplicación de tratados y convenios internacionales de protección de derechos humanos, como el aprobado con la oit (Convenio 169), el cual fue ratificado por Colombia en 1991, a partir del cual se establece que los pueblos indígenas tienen derecho a participar en aquellos procesos de desarrollo que afecten la vida, creencias, bienestar y las tierras que ocupan. En este sentido, el enfoque de análisis para este fenómeno ha estado matizado por el estudio normativo, particularmente en lo referente a la aplicación del convenio internacional 169 de la OiT.

De la conjugación de los anteriores derechos constitucionales fundamentales se desprenden prerrogativas para estos pueblos, que como colectividades o comunidades indígenas cuentan con las siguientes facultades.(i) Preservar y desarrollar sus tradiciones y costumbres, (ii) regirse por su derecho propio y por sus usos y costumbres, y (iii) gobernarse por sus propias autoridades. Esto significa que el Estado en su funcionamiento solo podrá limitar esa autonomía y tradiciones de las comunidades étnicas cuando la finalidad de esta tienda a realizar un valor o principio de mayor monto que el consignado en el respeto y protección de la diversidad étnica y cultural. 
La consulta previa es un derecho fundamental que aunque no está nombrado específicamente en la Carta Política, ha sido objeto de desarrollo jurisprudencial por mandato del Bloque de Constitucionalidad. Este ordena los lineamientos de la oIT, así como la inclusión y participación desde la perspectiva étnica de las comunidades que puedan verse afectadas al momento de aplicar medidas legislativas o administrativas por parte del Estado; así, y según la Corte Constitucional, adquiere connotación de derecho fundamental debido a que se constituye como el mecanismo idóneo para la preservación de la integridad social, económica y cultural de los grupos étnicos, asegurando de tal manera su subsistencia como grupo social dentro del Estado.

Bajo el Decreto 1320 de 1998, el cual establece los lineamientos para la explotación de recursos y el desarrollo de la consulta previa en territorios de comunidades indígenas y negras de la nación, se dispuso una definición restrictiva del territorio que ostentan dichos pueblos, pues como se consagró en el artículo segundo:

La consulta previa se realizará cuando el proyecto, obra o actividad se pretenda desarrollar en zonas de resguardo o reservas indígenas o en zonas adjudicadas en propiedad colectiva a comunidades negras. Igualmente, se realizará consulta previa cuando el proyecto, obra o actividad se pretenda desarrollar en zonas no tituladas y habitadas en forma regular y permanente por dichas comunidades indígenas o negras, de conformidad con lo establecido en el siguiente artículo.

En este sentido es de resaltar que las acciones que desee llevar a cabo el Estado y que requieren consulta previa, según lo dictaminado por el Convenio 169 de la OIT, son:

1. Medidas legislativas o administrativas susceptibles de afectarles directamente (Art. $6^{\circ}$, numeral 1, literal a).

2. Planes y programas de desarrollo nacional y regional susceptibles de afectarles directamente: "Los pueblos indígenas y tribales tienen el derecho de participar en la formulación, aplicación y evaluación de los planes y programas de desarrollo nacional y regional susceptibles de afectarles directamente" (Art. $7^{\circ}$, numeral 1).

3. Exploración y/o explotación de los recursos minerales, del subsuelo+ $\mathrm{u}$ otros existentes en las tierras de los grupos étnicos (Art. $15^{\circ}$, numeral 2).

4. Enajenación de sus tierras o de transmisión de sus derechos sobre estas fuera de su comunidad (Art. 17).

5. Creación de sus propias instituciones y medios de educación, siempre que tales instituciones satisfagan las normas mínimas establecidas por la autoridad competente (Art. 27).

6. La enseñanza en la lengua propia (Art. 28). 
Además, el desarrollo constitucional y doctrinario sobre la consulta previa ha incorporado escenarios en los cuales es obligatorio el llamado a una consulta previa. Así, según Gloria Amparo Rodríguez (2014), el derecho fundamental a la consulta previa ha sido equivocadamente interpretado en la medida en que se piensa que "solo se aplica en el caso de ejecución de proyectos o de explotación de recursos naturales en territorios indígenas, ya que de esta forma se ha interpretado el Artículo 330 de la Carta Política. Esto no es así, pues como ya lo hemos planteado, la obligación de la consulta previa tiene que ver con cualquier medida administrativa o legislativa que pueda afectar directamente a los pueblos indígenas (...) La Corte Constitucional (SU383/03) ha hecho mención a lo que ella misma ha denominado "el ámbito temático de la consulta previa" y ha precisado que esta se debe llevar a cabo respecto de cualquier aspecto que afecte directamente a las comunidades étnicas". Según esta perspectiva, es necesario adelantar el procedimiento de cabo consulta previa a pueblos étnicos cuando se quiera implementar por las autoridades:

a. Medidas legislativas:

i) Tratados internacionales.

ii) Leyes.

iii) Plan Nacional de Desarrollo.

b. Medidas administrativas:

i) Licencias ambientales.

ii) Permisos y autorizaciones ambientales.

iii) Permisos de investigación y acceso a recursos genéticos.

iv) Proyectos REDD+.

v) Erradicación de cultivos de uso ilícito.

vi) El ingreso de las Fuerzas Armadas.

vii) Reparación integral y restitución de derechos.

Como es posible observar, estos mecanismos administrativos permiten reafirmar la propuesta del Comité de Derechos Humanos de las Naciones Unidas, a través de la Observación General No 18, reafirmando los principios de no discriminación y la igualdad ante la Ley. A través de estos mecanismos se pueden establecer puentes de concertación entre Estado y sociedad civil (Guendel, 2002).

Solo a través de ello es posible alcanzar un goce efectivo de los Derechos Humanos en Colombia para todas las personas, en condiciones de igualdad y sin ningún tipo de discriminación. En este sentido, los mecanismos administrativos abordados anteriormente permiten contemplar los principios de interdependencia e integralidad de los derechos humanos, garantizando con ello la dependencia de algunos derechos con otros al punto que la lesión de tal derecho afecta a otro al que está conexo y que 
la concreción de un determinado derecho se relaciona con la satisfacción de otro, tal como fue desarrollado por la Conferencia Mundial sobre Derechos Humanos de Viena en 1993, acerca del principio de indivisibilidad, interdependencia y naturaleza no jerárquica de los derechos.

En el trasfondo de estos mecanismos se resalta la posibilidad para revertir la desigualdad real, derivada de las desigualdades socioeconómicas y políticas, a través de las cuales se han desarrollado las actividades sociales de grupos e individuos en el país. En este sentido, el derecho se visualiza como un mecanismo de integración social que alienta los establecimientos de normas de convivencia incluyentes, participativas y respetuosas de la diversidad y las garantías de los ciudadanos.

A través de los mecanismos administrativos desarrollados por el ordenamiento jurídico es posible delimitar la política pública, comprendiendo el problema público que la misma resolverá y la alternativa de solución ideal para reducir las tensiones y los conflictos sociales. Así mismo, se facilitarán los ámbitos de aplicación del derecho (contemplando los estándares nacionales e internacionales y definiendo los derechos y sus contenidos).

En este sentido, estos mecanismos facilitan la posibilidad de identificar las obligaciones estatales verificando los principios transversales que le son inherentes (participación, no discriminación e igualdad). En definitiva, el desarrollo de estos mecanismos permite contemplar la eficiencia de la arquitectura institucional y su impacto en las políticas, los programas y los proyectos que impactan los derechos fundamentales de los ciudadanos.

\section{Las políticas públicas con perspectiva de DDHH: necesidad de los acuerdos de La Habana}

A pesar de que Colombia ha gozado de una importante tradición democrática, amparada en unas élites nacionales formadas al amparo de las creencias en el republicanismo, las teorías liberales de la democracia moderna y la primacía del derecho (Cepeda Ulloa, 2004), este fenómeno se ha reproducido en forma paralela a contextos regionales de violencia y amenazas violentas al sistema político del Estado por parte de distintos actores (narcotráfico, guerrillas, paramilitares, macrodelincuencia). Por este motivo, dichas amenazas han interferido el marco de gobernabilidad que pretende el Estado social de derecho, pues:

...Uno de los aspectos más importantes para medir los índices de gobernabilidad de un ente territorial o de unos países en su totalidad tiene que ver con los índices 
de seguridad y la percepción de ésta en la sociedad. Dentro de la noción de seguridad, la criminalidad y la forma en cómo ésta se convierten en piedra angular de análisis y factores clave para la posibilidad de gobernar un territorio (Solano, 2010).

Esta dualidad (tradición democrática y baja gobernabilidad) está sustentada en las configuraciones locales provistas por el conflicto armado, enfocadas en la consolidación autoritaria del poder local (Gibson, 2006), que tienen como consecuencia la subsecuente disyunción entre contextos centrales-urbanos, influenciados por el Estado, y en los contextos periféricos-rurales, influenciados por actores armados ilegales (Gibson, 2006).

En este sentido es llamativo que la desaparición de las amenazas violentas al sistema político-social del país permitan una gestión más eficiente de las necesidades derivadas de los distintos sistemas sociales que regula el sistema político público, a través de los cuales es posible asegurar mayores márgenes de eficiencia y gobernabilidad de las instituciones públicas o, por lo menos, mejores mecanismos de participación y control de la administración pública.

Uno de los efectos más nocivos de la pervivencia del conflicto colombiano está relacionado con el uso de la violencia extrema y la depredación a gran escala en contra de la población civil (Centro Nacional de Memoria Histórica, 2013). Este fenómeno tiene un marco multicausal que incluye la ruptura en la postura estratégica general (fines, representaciones, iniciativas, medios y matriz socioespacial) de las guerrillas, con la subsecuente presión sobre la población civil (Lair, 2000, pág. 4).

En el marco de efectos más negativos de categorizar a la población civil como objetivo militar están las prácticas sistemáticas definidas por la 1448 de 2011, entre las cuales se incluyen las víctimas de crímenes de asesinato, desaparición forzada, tortura o tratos inhumanos o degradantes, violaciones, abusos o esclavitud sexual, reclutamiento forzado de niños, niñas y adolescentes o el desplazamiento forzado ocurridos dentro del conflicto.

Frente a este fenómeno, el Estado colombiano ha creado diversos mecanismos para gestionar la solución del conflicto armado y hacer la transición a un escenario de paz. En este último proceso con las FARC; es decir, el de las negociaciones de paz de La Habana, se torna indispensable un abordaje más profundo del desarrollo de políticas públicas con enfoque de DDHH, pues como resalta la propuesta de política integral de Derechos Humanos 2014-2034:

"El tránsito de la violencia a la construcción de la paz está estrechamente ligado a la vigencia y realización de los DDHH y la normativa humanitaria. El logro de los acuerdos políticos y sociales, y los mecanismos institucionales que faciliten la finalización de la 
confrontación armada, también implicarán las previsiones necesarias para el desarme, reincorporación y reintegración de excombatientes. El fortalecimiento del tejido social y de la institucionalidad requiere de delicados balances y ponderaciones alrededor de los valores fundantes de la sociedad colombiana" (Programa Presidencial DDHH y DIH, 2010, pág. 132).

Uno de los centros de gravedad de este nuevo marco de negociaciones lo constituye la atención del tema de las víctimas. Según el punto 5 de la agenda, el Gobierno y las FARC se comprometerán en varios temas. Por tal motivo, es de suponer que los principios que se han fijado las partes con el fin desarrollar este punto son esenciales, en tanto son el norte que debe guiar las medidas a tomar en esta temática (Gobierno Nacional-FARC EP, 2014).

El esclarecimiento de la verdad: dado que uno de los ejes centrales en la resolución del conflicto es la veracidad, la existencia de estos mecanismos con carácter judicial y extrajudicial se torna fundamental. Para evitar que tal como ha sucedido en algunos casos del proceso con los paramilitares los victimarios distorsionen los sucesos o alteren las narraciones, es preciso que las unidades de contexto de la Fiscalía tengan mayor injerencia en el diseño de los informes y que, en segundo lugar, las verdades contadas no necesariamente abran paso a procesos judiciales penales o administrativos.

La reparación de las víctimas: dado que uno de los asuntos problemáticos de la terminación del conflicto es la reparación, es importante la existencia de medidas de reparación colectiva, en algunos casos con enfoque diferencial (indígenas, ROM o negritudes), que permitan abordar macro contextos de la comisión de delitos. Así mismo, es indispensable la entrega de fondos de la organización FARC, con el fin de aportar medios para la reparación, sin que sea la variable económica el único, o central, eje de reparación. En este sentido las medidas simbólicas y culturales como estatuas, museos y actividades artísticas, etc. han de tenerse en cuenta.

Por otra parte, dada la enorme complejidad de las violencias locales que implican la categoría de "conflicto armado interno", en el caso colombiano es pertinente que las medidas adoptadas en el contexto local estén guiadas por la necesidad de que atiendan a solucionar problemáticas desde lo local, incorporando en dichas disposiciones los mecanismos anteriormente mencionados, con el propósito de facilitar mecanismos de participación para la inclusión de una perspectiva de DDHH. Esto implica que su construcción se dé desde un enfoque de arriba-abajo y no de abajo-arriba.

Lo planteado anteriormente implica reconocer que el éxito en la estabilización de las zonas afectadas por la violencia requiere diseñar mecanismos para conciliar los múltiples intereses que se manifiestan mediante la violencia y la construcción de confianza (entre grupos sociales en competencia), así sea a través de mecanismos 
informales y de las instituciones democráticas formales que permitan las garantías, condiciones y oportunidades que tienen todas las personas para interpelar, bajo el marco de la legalidad, los poderes públicos y privados por medio de mecanismos e instancias de efectiva participación y veeduría social; la necesaria vigilancia y fiscalización institucional de la gestión pública, así como el control social y político de la intervención de agentes públicos y privados; y la debida y periódica rendición de cuentas de la gestión e impacto de planes, programas y proyectos (Programa Presidencial DDHH y DIH, 2010, pág. 130).

En conclusión, una perspectiva que promueva los mecanismos de participación con la intención de promover un enfoque de derechos humanos en las actuaciones administrativas de las entidades públicas requiere, así mismo, que se abran canales para que las organizaciones insurgentes actúen como miembros políticos no armados (partido político) o armados de forma regulada (incorporación a organismos de seguridad). Esto implica limitar los efectos nocivos de la desmovilización, entre los cuales se encuentran las razones económicas, la falta de seguridad física, la falta de participación política, la falta de aceptación social y la ausencia del Estado, entre otros (Nussio, 2009, pág. 223).

A través de dichos mecanismos de participación en la conformación de las políticas públicas puede garantizarse un acompañamiento legítimo de los actores que están llamados a garantizar la implementación de los acuerdos (sociedad civil y partes de la negociación), más aún cuando el eje de este acuerdo parece estarse construyendo sobre la necesidad de atender a las víctimas del conflicto y en asegurar las garantías de no repetición.

Solo con una estrategia que permita una participación ciudadana más activa es posible garantizar el fortalecimiento de la sociedad y el Estado en el propósito de la realización de los DDHH, la ampliación y profundización de escenarios democráticos y la implementación de políticas que promuevan el respeto de la diferencia, la pluralidad y diversidad como activos fundamentales de la sociedad colombiana.

\section{Referencias bibliográficas}

Centro Nacional de Memoria Histórica (2013). Basta Ya: Memoria de Guerra y Dignidad. Bogotá: Imprenta Nacional. Recuperado de http://www. centrodememoriahistorica.gov.co/micrositios/informeGeneral/

Cepeda Ulloa, F. (2004). Fortalezas de Colombia. Bogotá: Ariel Ciencia Política.

Corte Constitucional (2002). Sentencia C-891 del 2002. Participación ciudadanaDerecho deber en tanto relación de lo público y lo privado/ 
Participación ciudadana-Servidores públicos y particulares. Bogotá (Colombia). Recuperado de http://www.corteconstitucional.gov.co/ relatoria/2002/c-891-02.htm

Corte Constitucional (2012), Sentencia T-348 del 2012. Derecho de participación. Bogotá (Colombia). Recuperado de http://www.corteconstitucional.gov. co/relatoria/2012/T-348-12.htm

Corte Constitucional (2013), Sentencia C-359 de 2013. Demanda de inconstitucionalidad por omisión legislativa en ley que promueve el acceso a la vivienda de interés social y a la vivienda de interés prioritarioprocedencia/omisión legislativa relativa en ley que promueve el acceso a la vivienda de interés social y vivienda de interés prioritario- Configuración por tratamiento discriminatorio en contra de la población gitana o rom y raizales, al excluirlos como beneficiarios del subsidio familiar de vivienda en especie para población vulnerable/COMUNIDADES RAIZALES-También constituye grupo étnico y cultural de la nación con reconocimiento constitucional y legal. Bogotá (Colombia). Recuperado de http://www. corteconstitucional.gov.co/RELATORIA/2013/C-359-13.htm

Corte Constitucional (2014), Sentencia T-297 de 2014. Pensión de invalidez como componente esencial de la seguridad social de personas en situación de discapacidad-Reiteración de jurisprudencial. Bogotá (Colombia). Recuperado de http://www.corteconstitucional.gov.co/ relatoria/2014/T-297-14.htm

Garretón, R. (2004). "La perspectiva de los derechos humanos en el diseño y ejecución de las políticas públicas", en: Garretón, R. et. al. El enfoque de los derechos humanos en las políticas públicas, Lima, Comisión Andina de Juristas, pp. 27-48.

Gibson, E. (2006). Autoritarismo subnacional: estrategias territoriales de control político en regímenes democráticos. Desafíos, 204-237.

Gobierno Nacional-FARC EP, (2014). “Declaración de principios para la discusión del punto 5 de la agenda: "víctimas". La Habana. Recuperado el 10 de 11 de 2015, de http://www.elpais.com.co/elpais/archivos/ ComunicadoConjuntoVictimas.pdf

Guendel, L. (2002). Políticas públicas y derechos humanos, Instituto Internacional de Gobernabilidad, www.iigov.org/documentos, consultado en octubre de 2015. 
Lair, E., Ramírez, W. y Nasi, C. (2003). La guerra Civil. Revista de Estudios Sociales(14), 119-126.

Nussio, E. (2009) ¿Reincidir o no? Conceptos de la literatura internacional aplicados al caso de desarme, desmovilización y reintegración de las Autodefensas Unidas de Colombia. En Pensamiento Jurídico (26), 214-235.

Nussio, E. (2009). ¿ ¿Reincidir o no? Conceptos de la literatura internacional aplicados al caso de desarme, desmovilización y reintegración de las Autodefensas Unidas de Colombia. Pensamiento Jurídico (26), 214-235.

Organización de las Naciones Unidas para la Agricultura y la Alimentación (2001). Conflictos y manejo de recursos naturales, Roma. Italia. Obtenido de: http://www.fao.org/forestry/21575-09684b8bbf0673156ec237ead64c08 2b3.pdf

Organización de las Naciones Unidas. (2008). Declaración Universal de los Derechos Humanos, United Nations.

PNUD (1994). Informe Sobre Desarrollo Humano. Nueva York: México.

PNUD (2003). Conflicto, Callejón con Salida. Naciones Unidas, 510.

PNUD (2006). El poder económico ilegal: una amenaza para las elecciones. Hechos del Callejón, 12. Obtenido de http://www.pnud.org.co/hechosdepaz/echos/ pdf/12.pdf

PNUD. (2012). Pueblos indígenas. Diálogos entre culturas. Bogotá: INDH.

Programa Presidencial DDHH y DIH (2010). De la Violencia a la Sociedad de los Derechos: Propuesta para la Politica de Derechos Humanos en Colombia 2014 - 2034. Bogotá: Colombia.

Rodríguez, G. (2014). De la Consulta Previa al consentimiento previo, libre e informado: Bogotá (Colombia), Editorial Universidad del Rosario.

Sañudo, M. y Sánchez, R. (2014), Enfoque Basado en Derechos humanos. Guía para su uso en incidencia política y políticas públicas: Bogotá (Colombia), Editorial Pontificia Universidad Javeriana.

Solano, M. (2010). Criminalidad, territorio y gobernabilidad. En Calderón, E., Jost, S. y (Edi), Más allá de la seguridad democrática. (pp.. 325-336). Bogotá: Konrad Adenauer Stiftung. 